\title{
Article \\ Biodegradable Silver Nanoparticles Gel and Its Impact on Tomato Seed Germination Rate in In Vitro Cultures
}

\author{
Miłosz Rutkowski ${ }^{1,2}$, Lidia Krzemińska-Fiedorowicz ${ }^{3}$, Gohar Khachatryan ${ }^{4}\left(\mathbb{D}\right.$, Karol Bulski ${ }^{5}$ (D), Anna Kołton ${ }^{6}$ (D) \\ and Karen Khachatryan $3, * \mathbb{D}$
}

1 Students' Scientific Society of Biotechnologists "Helisa", Faculty of Biotechnology and Horticulture, University of Agriculture in Krakow, Mickiewicz Ave. 21, 31-120 Krakow, Poland; miloszr131@gmail.com

2 Students' Scientific Society of Food Technologists, Faculty of Food Technology, University of Agriculture in Krakow, Mickiewicz Ave. 21, 31-120 Krakow, Poland

3 Department of Chemistry, Faculty of Food Technology, University of Agriculture in Krakow, Mickiewicz Ave. 21, 31-120 Krakow, Poland; lidia.krzeminska@urk.edu.pl

4 Department of Food Analysis and Evaluation of Food Quality, Faculty of Food Technology, University of Agriculture in Krakow, Mickiewicz Ave. 21,31-120 Krakow, Poland; gohar.khachatryan@urk.edu.pl

5 Faculty of Agriculture and Economics, University of Agriculture in Krakow, Mickiewicz Ave. 21, 31-120 Krakow, Poland; karol.bulski@urk.edu.pl

6 Faculty of Biotechnology and Horticulture, University of Agriculture in Krakow, Mickiewicz Ave. 21, 31-120 Krakow, Poland; anna.kolton@urk.edu.pl

* Correspondence: karen.khachatryan@urk.edu.pl; Tel.: +48-12-662-41-39

\section{check for}

updates

Citation: Rutkowski, M.;

Krzemińska-Fiedorowicz, L.;

Khachatryan, G.; Bulski, K.; Kołton,

A.; Khachatryan, K. Biodegradable

Silver Nanoparticles Gel and Its

Impact on Tomato Seed Germination

Rate in In Vitro Cultures. Appl. Sci.

2022, 12, 2722. https://doi.org/

10.3390/app12052722

Academic Editor:

Ioannis Kartsonakis

Received: 6 February 2022

Accepted: 4 March 2022

Published: 6 March 2022

Publisher's Note: MDPI stays neutral with regard to jurisdictional claims in published maps and institutional affiliations.

Copyright: (c) 2022 by the authors. Licensee MDPI, Basel, Switzerland. This article is an open access article distributed under the terms and conditions of the Creative Commons Attribution (CC BY) license (https:// creativecommons.org/licenses/by/ $4.0 /)$.

\begin{abstract}
Nanotechnology plays an important role in many fields of science and the economy. A special example of nanostructures is silver nanoparticles (AgNPs) created following the principles of green chemistry, i.e., without the use of toxic reducing compounds. The common tomato (Solanum lycopersicum) is a popular vegetable whose germination and growth process are studied by using, e.g., in vitro cultures. The aim of the experiment was to evaluate the inhibitory effect of the biodegradable gels containing silver nanoparticles on the development of microbial infection and to evaluate their influence on the germination degree of Tomato (Solanum lycopersicum) seeds in in vitro plant cultures. Based on macroscopic and microscopic observations, all experimental samples showed the presence of Gram-positive bacilli as well as mould fungi of the genus Rhizopus, Alternaria and Aspergillus. The study showed that the biocomponents containing silver nanoparticles obtained by using xylose as a reducing agent limit the development of microbial infection and stimulate the germination rate of tomato seeds. They could find their application as biodegradable raw materials in the production of modern disinfecting preparations for research in in vitro cultures. This study allowed to identify new research directions, especially to evaluate the metabolic regulation of seedlings treated with biodegradable silver nanoparticles.
\end{abstract}

Keywords: AgNPs; sodium alginate; bacteria; fungi; tomato; in vitro culture

\section{Introduction}

In the 21st century, nanotechnology is an interdisciplinary branch of science, describing structures sized $100 \mathrm{~nm}$ or less, allows characterizing innovative possibilities of using nanoscale metals with biological properties important for the industry [1-3]. Metal nanoparticles find interdisciplinary applications in various fields, e.g., silver is used in the production of food packaging, cosmetics or medical bandages [4-6]. The synthesis of silver nanoparticles can be physical, chemical or biological. The type of the used method influences the properties of the obtained nanostructures $[7,8]$. One of the most desirable properties exhibited by metal nanoparticles seems to be antimicrobial activity resulting from the shapes assumed in the structure of the carrier in which they are embedded. This biological activity described in the literature is based on the interaction of nanostructures with microbial cell surfaces, influencing metabolic processes in microbial cells, which in turn lead to the 
destruction of internal structures, inhibition of microbiota development and microbial contamination [9-12]. A special example of a carrier stabilizing the formation of silver nanoparticles are substances of natural origin, which show innovative properties that allow the creation of plastic gels. Biopolymers as biodegradable and intranasalable substances have the advantage of low toxicity to the ecosystem because they quickly decompose into basic compounds. Among such substances, examples of sodium alginate or chitosan can be cited [13-17]. Sodium alginate is a biopolymer consisting of D-mannuronic and L-guluronic acid. In the food industry, it is used to create modern food packaging. As a substance derived from the natural environment, it is a non-toxic matrix for the creation of components containing active biological factors, e.g., silver nanoparticles $[18,19]$. On the other hand, chitosan is a biodegradable polymer used in the food industry and bioengineering for the process of sprinkling active substances. When using chitosan, it is possible to create components containing biologically active factors [20-22]. Tomato (Solanum lycopersicum) is a popular vegetable belonging to the Solanaceae family. Tomato fruits are an important part of the human diet due to the wide range of bioactive compounds such as carotenoids, flavonoids, antioxidants and anti-cancer compounds [23-25]. The production of tomato fruit is one of the largest undertakings in the world. In 2018, it reached 182 million tonnes. The largest tomato producing countries are the United States, China and Turkey, while Spain and Italy are the largest tomato producers on the European market [26].

The tomato is also an example of a model organism [27] and can be used in a variety of in vitro experiments [28-30]. In vitro cultivation requires prior preparation of the plant material-sterilisation. If the culture is carried out from seeds, surface sterilisation of the seeds is usually applied [31]. Many methods of surface sterilisation of seeds are known [32,33], but they are not always effective. Many authors observed culture contamination despite the use of surface sterilisation and high care during handling or with prolonged treatment with disinfectants, lower levels of germination and seedling survival were observed [32]. The cause of such phenomenon may be microorganisms located inside the seeds [34]. Plant organisms, including the tomato (Solanum lycopersicum), can become a reservoir for many strains of microorganisms. These microorganisms can survive inside the seed structure of dormant seeds and, as a result of the germination process, move to the newly formed seedling. Potential microorganisms that inhabit the plant are bacteria of the genus Bacillus, Pseudomonas, Acinetobacter and Staphylococcus. The large diversity of plant microbiota results from changes in the environment in which the plant grows $[28,35,36]$. Infection of the culture may be observed after seed rupture-germination begins. Decontamination of such a culture is very difficult. The phenomenon forces the need to find an alternative method of limiting microbial growth using innovative technology, the use of which would be consistent with the postulates of "green chemistry", and therefore potentially safe for the proper growth of plants and the development of the natural environment.

The aim of this study was to produce biodegradable alginate-based material containing silver nanoparticles, describe their structure and properties and to test their applicability during in vitro culture of tomato using seeds. It was hypothesised that an appropriate concentration of nanoparticles would reduce pathogen growth but not seed germination.

\section{Materials and Methods}

\subsection{Synthesis of Gels with Silver Nanoparticles}

Reagents used in the synthesis of nanosilver containing gels.

Chemical reagents were used to prepare the nanocomposites, i.e., sodium alginate (Sigma-Aldrich), glycerine (99.5\%, Sigma-Aldrich, Poznan, Poland) —as an excipient (plasticiser), $\mathrm{AgNO}_{3}$ (Aldrich, Poznan, Poland, 99.99\%, PubChem CID: 24470), $\mathrm{NH}_{3}$ (SigmaAldrich, Poznan, Poland, PubChem CID: 18944693) and D-(+)-xylose (Sigma-Aldrich, Poznan, Poland, BioXtra, PubChem CID: 135191) and deionized water.

A $1.5 \%$ sodium alginate solution was prepared by gelatinizing $3 \mathrm{~g}$ of sodium alginate (Sigma-Aldrich) with $197 \mathrm{~g}$ of deionized water in a magnetic stirrer (Heidolph MR3002) 
with a connected thermostat $\left(70^{\circ} \mathrm{C}\right)$. After completion of the gelatinizing process, $1.5 \mathrm{~g}$ of glycerine $(99.5 \%$, Sigma-Aldrich) was added as a plasticizer. $200 \mathrm{~mL}$ of the polysaccharide gel was stirred and $2 \mathrm{~mL}$ of Tollens solution was added. $1.5 \mathrm{~mL}$ of $4 \% \mathrm{D}-(+)$-xylose were added to the gel, the temperature was reduced to $55^{\circ} \mathrm{C}$ and the mixture was stirred for another $10 \mathrm{~min}$. The final nanosilver concentration in the gel was $150 \mathrm{ppm}$. Then, dilutions of gel solutions containing silver nanoparticles in three concentrations in the volume ratio $(1: 2),(1: 5)$ and (1:10) were prepared, which allowed to obtain three concentrations of silver nanoparticles: $75 \mathrm{ppm}, 30 \mathrm{ppm}$ and $15 \mathrm{ppm}$. A sterile water solution was determined as a control.

\subsection{UV-VIs Absorption Spectrophotometry}

The UV-VIS absorption spectra were obtained using a Shimadzu 2101 scanning spectrophotometer (Shimadzu, Kyoto, Japan), with a range covering 200-800 nm.

\subsection{FTIR-ATR Spectrophotometry of Composites}

The FTIR spectra of the produced composites were analyzed within the $4000-700 \mathrm{~cm}^{-1}$ range, using a MATTSON 3000 FT-IR spectrophotometer (Madison, WI, USA) equipped with a 30SPEC 30 Degree Reflectance adapter (MIRacle ATR, PIKE Technologies Inc., Madison, WI, USA).

\subsection{Scanning Electron Microscopy (SEM)}

The shape and size of the obtained nanostructures characterized using a JOEL 7550 high-resolution SEM (Akishima, Tokyo, Japan) equipped with a Retractable BackscatteredElectron detector (RBEI) (Akishima, Tokyo, Japan).

\subsection{Tomato In Vitro Cultures-Germination and Infection Test}

Sterile autoclaved standard MS [37] medium (1/2 MS, $0.4 \%$ phytagel, $1 \%$ sucrose, $\mathrm{pH}$ 5.8) was poured on the Petri dishes, then $1 \mathrm{~mL}$ of prepared gels with silver nanoparticles in different concentrations (75 ppm, $30 \mathrm{ppm}, 15 \mathrm{ppm}$ ) were poured on the surface of the solidified medium. It was observed for 7 days to see if any infection appeared. The gels were free of pathogens and the experiment could be continued (data not presented). In the subsequent experiments, tomato seeds (Solanum lycopersicum) of the cultivar Kmicic (PlantiCo, Stare Babice, Poland) were used. Following plates were prepared in a similar manner (sterile $1 / 2 \mathrm{MS}, 0.4 \%$ phytagel, $1 \%$ sucrose, $\mathrm{pH} 5.8$ ), and $1 \mathrm{~mL}$ of different concentrations (75 ppm, $30 \mathrm{ppm}, 15 \mathrm{ppm}$ ) of prepared nanosilver gels were poured onto the surface of the solidified medium under sterile conditions. Control plates were treated with sterile distilled water. Twenty non-sterile tomato seeds were sown on each plate (Experiment 1). The plates were closed and kept in the dark at $20^{\circ} \mathrm{C}$. Every $24 \mathrm{~h}$ the degree of contamination of the tested plates as well as seed germination was checked. The number of germinated seeds in each plate was counted and expressed as a percentage of all the seeds sown on a plate (germination rate). In addition, the number of seeds at which infections occurred was counted and expressed as a percentage of all seeds in the plate (infection rate). The experiment lasted $120 \mathrm{~h}$. Each treatment was performed in 3 replications.

Another experiment was conducted on similarly prepared plates (sterile 1/2 MS, $0.4 \%$ phytagel, $1 \%$ sucrose, $\mathrm{pH} 5.8$ ) with the difference that before sowing the seeds were immersed in different solutions: sterile water, nanosilver solutions of different concentration (75 ppm, $30 \mathrm{ppm}, 15 \mathrm{ppm}$ ), and subjected to surface sterilisation with an aqueous solution of sodium hypochlorite (Experiment 2). For surface sterilization of seeds with hypochlorite, $0.1 \% \mathrm{NaOCl}$ dissolved in water was used, seeds were treated with the solution for $5 \mathrm{~min}$, followed by two rinses with $70 \%$ ethanol and two rinses with sterile water. After the tomato seeds were immersed $(5 \mathrm{~min}$ ) in the appropriate solutions, they were sown into the prepared plates, 20 seeds per one. Three plates were prepared for each treatment. The plates were closed and kept in the dark at $20^{\circ} \mathrm{C}$. Every $24 \mathrm{~h}$ the germination rate and the infection rate were checked as described above. The experiment lasted $120 \mathrm{~h}$. 


\subsection{Identification of Isolated Microorganisms}

The isolated microorganisms were identified based on macroscopic and microscopic characterization. The macroscopic characterization of bacterial colonies included the determination of the morphological features of the colony (size, shape, elevation or profile, transparency, colour of the colony, structure and smell). The microscopic characterization of the bacterial colonies was based on the morphological evaluation of the Gram-stained preparations. The microscopic analysis provided data on: the size of the cells, their shape and arrangement in relation to each other. The macroscopic analysis of fungi included the determination of morphological features: colony size in a Petri dish, colony appearance, consistency, degree of fluffiness, colour, smell, possible pigment diffusion into the substrate and the separation of substance droplets. In the microscopic characterization of the colonies, the preparations in the Lugol's liquid were observed. Size, shape, surface appearance and arrangement of spores, size and shape of conidiophores were determined [38-41].

\subsection{Statistical Analysis}

Statistical analysis of the obtained results was performed with the use of Statistica version 13.3. Objects were compared using analysis of variance and Fisher's Least Significant Difference (LSD) test. The letters represent homogeneous groups determined with the assumed significance level of 0.05 . Lack of letters means no statistically significant differences. Statistical analysis was performed for each term separately.

\section{Results}

\subsection{UV-VIs Absorption Spectrophotometry}

UV-VIS analysis indicated the formation of Ag nanoparticles, a typical peak in the range of 350-600 nm was obtained (Figure 1) [18,42].

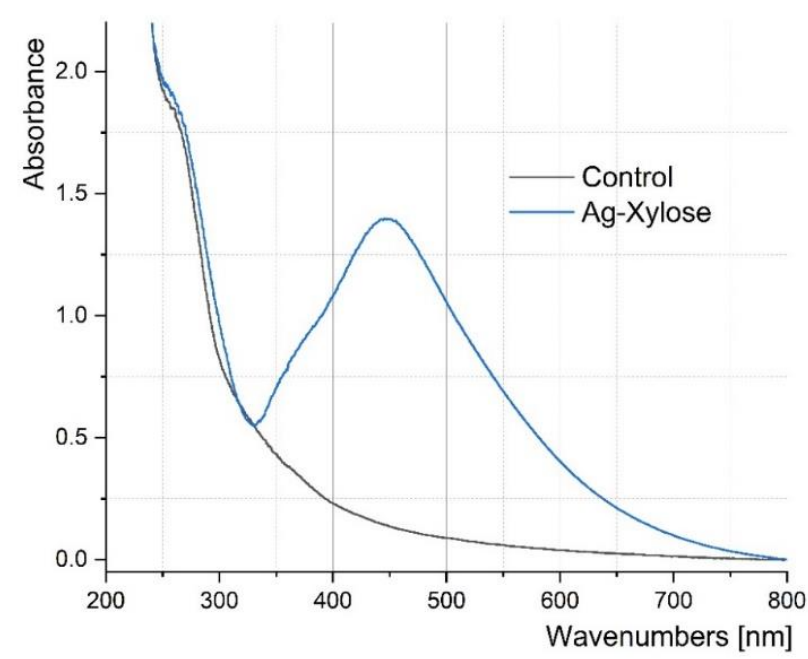

Figure 1. UV-VIs spectra of control (black line) and Ag-xylose (blue line).

\subsection{Scanning Electron Microscopy (SEM)}

The width of the peak band indicates that the formed nanoparticles are characterized by different sizes, which has been confirmed by images from a scanning electron microscope.

The obtained silver nanoparticles were characterized by regular and spherical shapes, their sizes varied between 5-20 nm (Figure 2). 


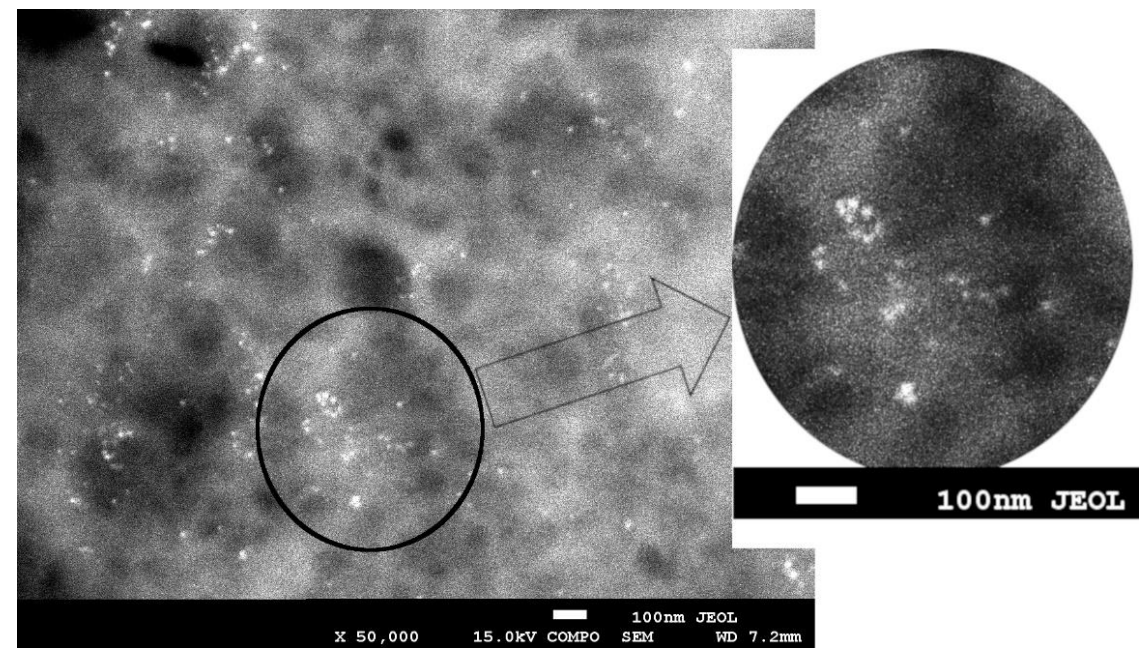

Figure 2. SEM micrographs of AgNPs taken at $\times 50,000$ magnification.

\subsection{FTIR-ATR Spectrophotometry}

In the presented FTIR spectra (Figure 3) we observed the characteristic spectrum of the sodium alginate with a broad band centred at approximately $3210 \mathrm{~cm}^{-1}$ (hydroxyl groups stretching), low intensity bands at about $2915 \mathrm{~cm}^{-1}$ (attributed to $-\mathrm{CH}_{2}$ groups), two peaks at $1603 \mathrm{~cm}^{-1}$ and $1408 \mathrm{~cm}^{-1}$ (asymmetric and symmetric stretching modes, respectively, of carboxylate salt groups (-COONa), and a number of vibrations in the range of 1100-990 $\mathrm{cm}^{-1}$ (glycoside bonds in the polysaccharide (C-O-C stretching) [43]. The absence of significant changes in the shape of the obtained spectra indicates that the synthesis of nanometals did not cause structural changes in the alginate polymer.

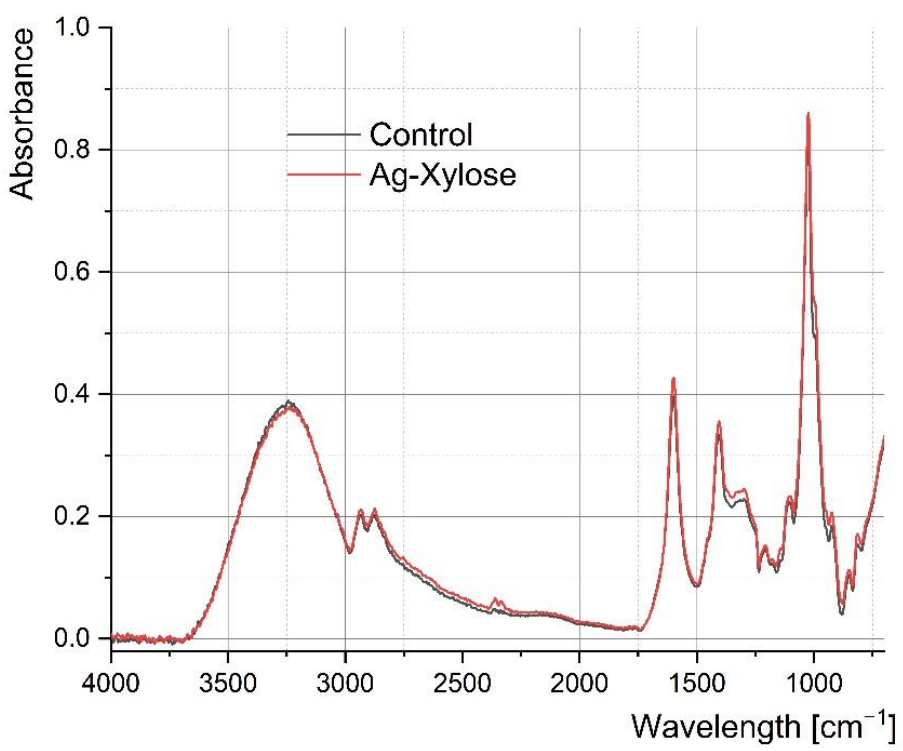

Figure 3. FTIR absorption spectra of control (black line) and Ag-Xylose (red line).

\subsection{Germination and Infection Rate in Tomato In Vitro Culture \\ 3.4.1. Experiment 1}

In the first experiment, silver nanoparticle solutions of different concentrations and water as control were applied to a sterile medium in a plate. The first infections (Figure 4) were found $48 \mathrm{~h}$ after the start of the experiment therefore the results after $24 \mathrm{~h}$ are not shown in the figure. The highest infection rate was recorded in the control (sterile water applied to the surface of the medium) and the injection of silver nanoparticles reduced the infection rate at $48 \mathrm{~h}$ of the experiment. The number of infections increased over time. 
After $120 \mathrm{~h}$ of the experiment, the dishes treated with water and the lowest concentration of nanoparticles were all infected. However, the application of $75 \mathrm{ppm}$ nanoparticles significantly reduced the number of infections.

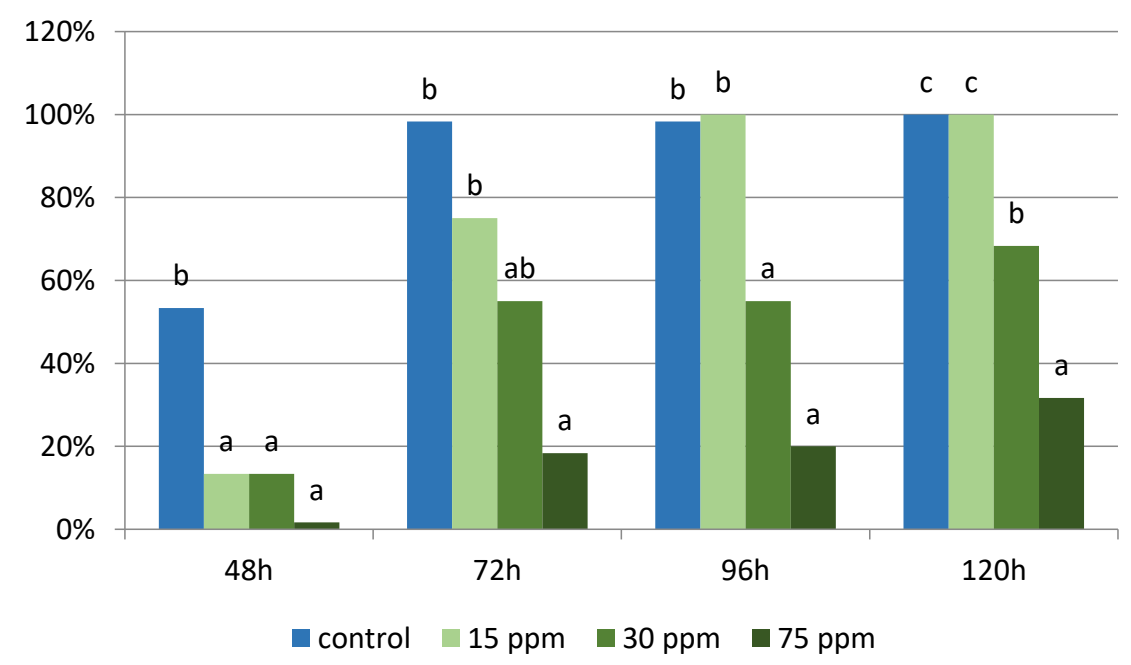

Figure 4. Rate of infections of tomato seed culture after application of different concentrations of silver nanoparticles (75 ppm, $30 \mathrm{ppm}$ and $15 \mathrm{ppm}$ ). The control sample was treated with sterile water. Treatments were compared using analysis of variance and Fisher's LSD test for each term separately. Parameters in columns denoted with the same letters (a. b. c.) do not differ statistically at the confidence level of $p<0.05$.

In the case of the germination rate, the first seeds started to germinate after $48 \mathrm{~h}$ in all experimental trials (Figure 5). However, during this time the seeds germinated similarly, regardless of the treatment applied. The differences in seed germination rate were already noted after $72 \mathrm{~h}$ of observation. The highest number of seeds germinated was observed after the application of $75 \mathrm{ppm}$ of silver nanoparticles and the lowest in the control $(72 \mathrm{~h}$ ). At the last observation term, it was noted that the application of all concentrations of silver nanoparticles significantly improved germination, while seeds treated with water germinated the worst.

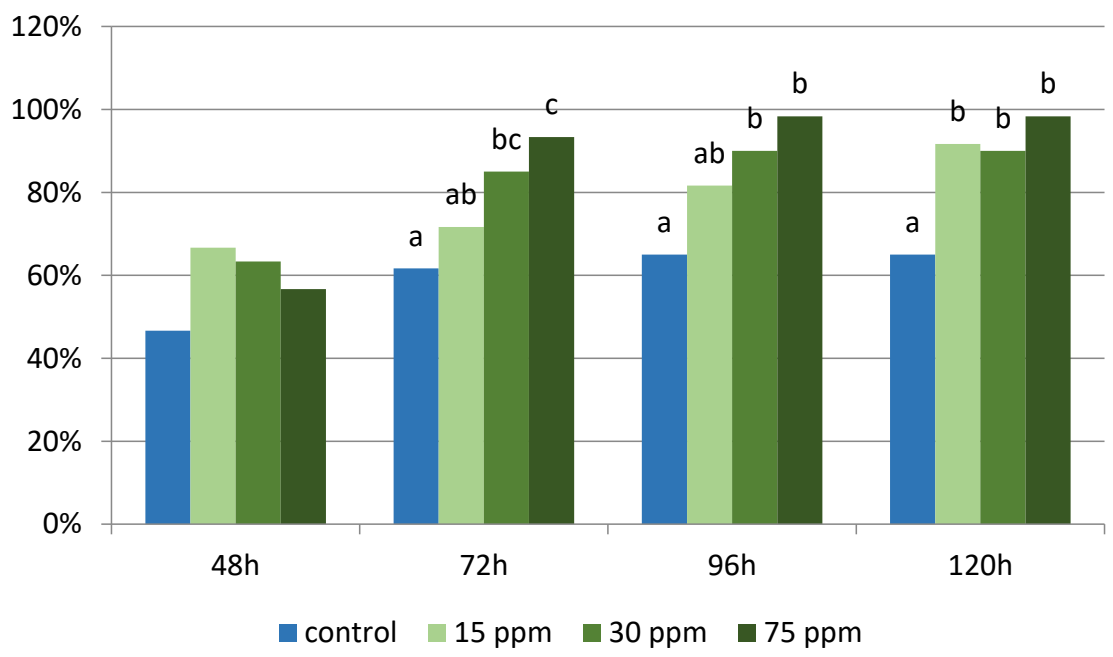

Figure 5. Germination of tomato seeds in culture after application of different concentrations of silver nanoparticles (75 ppm, $30 \mathrm{ppm}$ and $15 \mathrm{ppm}$ ). The control sample was treated with sterile water. Treatments were compared using analysis of variance and Fisher's LSD test for each term separately. Parameters in columns denoted with the same letters (a. b. c.) do not differ statistically at the confidence level of $p<0.05$. Lack of letters means no statistically significant differences. 


\subsubsection{Experiment 2}

In the second experiment, seeds were soaked in the respective solutions before sowing onto the prepared medium. As in the first experiment, the first infections were recorded after $48 \mathrm{~h}$ of the experiment (Figure 6). During this observation, the highest number of infections was recorded in seeds pre-treated with sterile water and the lowest in those treated with hypochlorite. The application of silver nanoparticles reduced the infection rate compared to the control. Although no infections were observed in seeds dipped in hypochlorite after $48 \mathrm{~h}$, infections in these seeds appeared over time. It is noteworthy that after $120 \mathrm{~h}$ from the start of the experiment, infection levels in seeds treated with hypochlorite and nanosilver solutions at concentrations of $75 \mathrm{ppm}$ and $30 \mathrm{ppm}$ were similar and significantly lower than those of the control or the lowest concentration of naonoparticles. The percentage of germination is shown in Figure 7. The first germinating seeds were observed $48 \mathrm{~h}$ after sowing. There was no difference in germination as a result of the applied solutions into which the seeds were immersed before sowing.

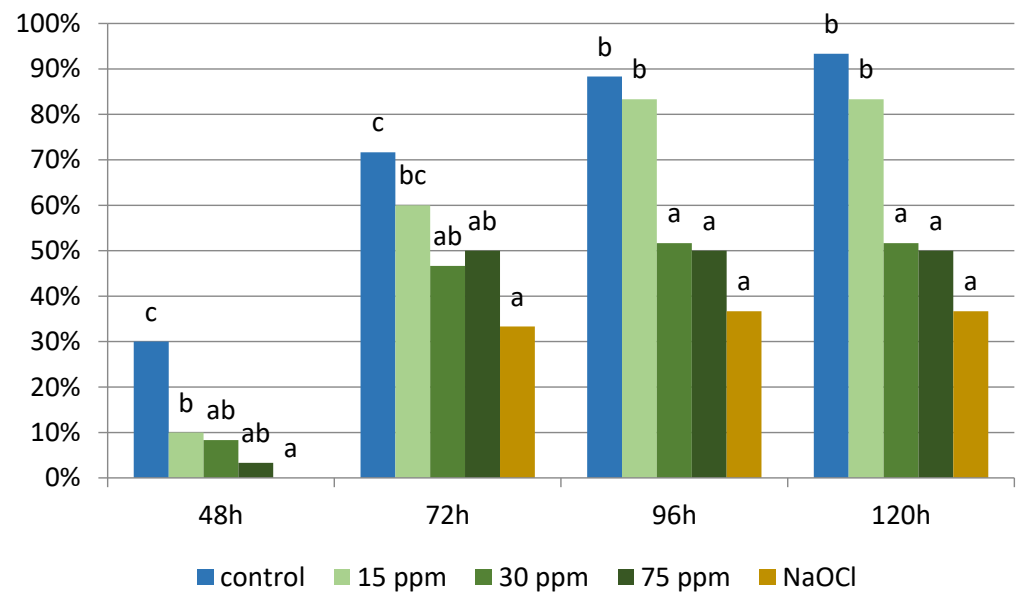

Figure 6. Rate of infections of tomato seed after immersion in solutions of different concentrations of silver nanoparticles (75 ppm, $30 \mathrm{ppm}$ and $15 \mathrm{ppm}$ ) or sodium hypochlorite $(\mathrm{NaOCl})$. The control sample was treated with sterile water. Treatments were compared using analysis of variance and Fisher's LSD test for each term separately. Parameters in columns denoted with the same letters (a. b. c.) do not differ statistically at the confidence level of $p<0.05$.

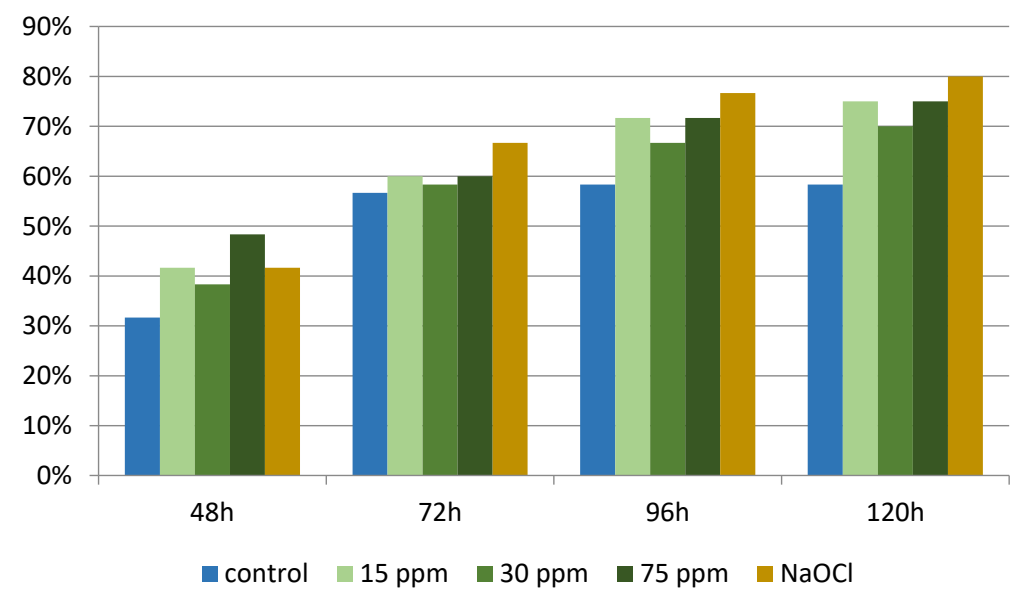

Figure 7. Germination of tomato seeds after immersion in solutions of different concentrations of silver nanoparticles (75 ppm, $30 \mathrm{ppm}$ and $15 \mathrm{ppm}$ ) or sodium hypochlorite ( $\mathrm{NaOCl})$. The control sample was treated with sterile water. Treatments were compared using analysis of variance and Fisher's LSD test for each term separately. The letters represent homogeneous groups determined with the assumed significance level of 0.05 . Lack of letters means no statistically significant differences. 


\subsection{Isolated Microorganisms}

In all experimental trials, the presence of microorganisms was found. In the case of bacteria, the Gram-positive bacilli were found. In the case of fungi, the genus of Alternaria, Rhizopus and Aspergillus were found.

\section{Discussion}

Preventing the development of undesirable microbiota seems to be one of the main topics of research on the practical application of preparations containing active agents such as silver nanoparticles, as evidenced by the works [9-11,44] carried out over several years. Due to their antimicrobial activity, components containing biologically active silver nanoparticles could be a potential alternative to disinfectants used so far in in vitro cultures. However, for this to happen, a number of analyses should be carried out to assess the degree of germination of seeds and other plant structures used in vitro. The potential lack of necrotic changes in seedlings, presented in this paper, raises some hopes for a non-toxic, time-delayed release of silver nanoparticles from the structure of sodium alginate.

MS medium is commonly used in in vitro cultures of tomato [45]. Sucrose is usually added to the medium as an easy source of carbon chains for plants [46,47], but it can also be used by microorganisms [48]. Sometimes sugar is omitted from the nutrient solution to reduce infection [34], but there is a risk of slower plant growth. The possibility of using silver nanoparticles to decontaminate Arabidopsis seeds and tomato leaf explants were demonstrated by Mahna and co-worker [49]. However, it was observed that with complete sterilising effect (no culture infection) long exposure to silver nanoparticle solutions (30 and $60 \mathrm{~min}$ ) has an inhibitory effect on Arabidopsis seed germination and high concentrations of silver nanoparticles (250-2000 ppm) even at shorter exposure inhibit germination. Therefore, silver nanoparticles are a promising sterilizing agent but it is important to select an appropriate concentration and assess the risk of seed germination inhibition. Toxic effects of silver nanoparticles on plants in vitro cultures were also observed in Aldrovanda vesiculosa [50]. Therefore, work on the application of nanoparticles to in vitro cultures is still ongoing and requires, on the one hand, the search for new methods of producing silver nanoparticles and, on the other, testing their effect on specific cultures. In the presented work, a modern method of nanoparticle production using alginate was used and, most importantly, no toxic effect on germinating tomato plants was observed at any of the concentrations used. However, not every concentration used was equally effective in protecting against culture infection. In experiment 1 (non-sterile seeds were placed on culture media), the application of a 75 ppm silver nanoparticle solution gave the highest inhibitory effect on infection development. In contrast, the application of a $15 \mathrm{ppm}$ solution did not reduce the development of infection. In the second experiment (seeds were treated with different solutions before placing them on the plates), the greatest reduction in infection development was obtained with a 75 and $30 \mathrm{ppm}$ solution of nanosilver and a solution of sodium hypochlorite. Despite the best performance of these solutions, infections of $50 \%$ were still observed. In addition, in other studies, the appearance of microorganisms was observed after the application of hypochlorite [34]. Infections were also observed in barley embryo cultures after hypochlorite treatment [51]. The addition of silver nanoparticles to the MS medium decreased the frequency of these infections which points to the effectiveness of nanosilver in reducing infection-as in our experiments. The use of silver nanoparticles as a solution poured on the surface of the medium in the first experiment improved seed germination compared to the control. In the second experiment, seeds germinated at similar levels in all treatments. In the study by Bill et al. [52], similarly to this study, the stimulation of plant seedlings growth was demonstrated on the example of garden petunias in in vitro cultures. Dehkourdi et al. [53] showed that with an increased concentration of $\mathrm{TiO}_{2}$ nanoparticles, the germination process of parsley seeds (Petroselinum crispum) was stimulated in in vitro cultures. Similarly, Shinde et al. [54] found the stimulation of germination of corn seeds (Zea mays) caused by the presence of nanoparticles in culture. Therefore, it can be said that nanoparticles can be potential biostimulators in the 
process of plant germination and the applied in the present experiment concentrations of silver nanoparticles had no toxic effect and did not reduce tomato seed germination, and in some cases even stimulated germination.

One of the new ideas for human, animal or plant pathogens prevention is the composition of new materials with antibacterial or antifungal properties, with long-acting times and without negative environmental impact. One of the potential solutions are metallic nanoparticles (NPs), especially silver nanoparticles. Their antimicrobial effect results from the cell membrane and DNA damages or interaction with enzymes from thiol groups [55,56]. It should be emphasized that the morphology, stability, type, aggregation, and concentration of nanoparticles are the main properties that determine their toxic effect on biological systems [57]. The results of our study showed that for both non-sterile and sterile seeds in vitro cultures, the lowest value of the infection rate was observed for the concentration of $75 \mathrm{ppm}$ of AgNPs. The worst effect of AgNPs was observed at a concentration of $15 \mathrm{ppm}$. Therefore, our research confirmed the influence of the concentration of metal nanoparticles on antimicrobial properties, which was described by other authorshigher concentration of NPs increases their antimicrobial properties [58-61]. However, the concentrations of AgNPs, used in our research, were too low to completely inhibit the growth of microorganisms, because in all experimental trials, the presence of microbes was found. The results of our research showed the growth of Gram-positive bacilli as well as Alternaria, Rhizopus and Aspergillus fungi (in all samples). All these microorganisms are common in the natural environment. Although previous biological studies reveal potential inhibition of growth of Gram-positive and Gram-negative bacteria as well as microscopic fungi as a result of interactions of NPs [62-66], the nanotoxicity towards Gram-positive cells was significantly less, possibly due to the presence of a thicker peptidoglycan layer [67]. Antifungal properties of AgNPs usually concern the study of various types of yeast, there are merely a few studies concerning the interaction of molds with AgNPs. The research by Żarkowska et al. [68] showed that the sensitivity of mold fungi to AgNPs depends on the mould species. The study also showed that, for example, concentration $2.5 \mathrm{mg} / \mathrm{L}$ of AgNPs was sufficient for the inhibition of Aureobasidium pullulans, but 10 times higher concentration was needed for the Aspergillus niger growth inhibition [69].

\section{Summary}

Based on the conducted research, it is concluded that biocomponents containing silver nanoparticles obtained by using xylose as a reducing agent limit the development of microbial infection and stimulate the germination degree of tomato seeds. They could find their application as biodegradable raw materials in the production of modern disinfecting preparations for the research in in vitro cultures. Work on the growth of plant seedlings treated with metal nanoparticles demonstrates the stimulating effect of nanostructures.

This experiment is a pilot study, based on which further analyses of the effect of components containing biologically active silver nanoparticles on the germination of vegetable seeds and the inhibition of microbial infection of seeds will be carried out in the future.

Author Contributions: Conceptualization, M.R., A.K. and L.K.-F.; methodology, G.K., K.K., A.K., K.B. and M.R.; software, K.K., A.K. and K.B.; formal analysis, K.K., A.K., G.K., L.K.-F. and M.R.; investigation, K.K., G.K. and A.K.; writing—original draft preparation, M.R., A.K., G.K. and K.B.; writing-review and editing, K.K., G.K. and A.K.; visualization, K.K., A.K. and K.B.; supervision, G.K. and A.K. All authors have read and agreed to the published version of the manuscript.

Funding: This research was funded by a subsidy of the Ministry of Science and Higher Education for the University of Agriculture in Krakow.

Institutional Review Board Statement: Not applicable.

Informed Consent Statement: Not applicable.

Data Availability Statement: The data presented in this study are available on request from the corresponding author. 
Conflicts of Interest: The authors declare no conflict of interest.

\section{References}

1. Lashin, I.; Fouda, A.; Gobouri, A.A.; Azab, E.; Mohammedsaleh, Z.M.; Makharita, R.R. Antimicrobial and In Vitro Cytotoxic Efficacy of Biogenic Silver Nanoparticles (Ag-NPs) Fabricated by Callus Extract of Solanum incanum L. Biomolecules 2021, 11, 341. [CrossRef] [PubMed]

2. Parisi, C.; Vigani, M.; Rodríguez-Cerezo, E. Agricultural Nanotechnologies: What are the current possibilities? Nano Today 2015, 10, 124-127. [CrossRef]

3. Valdiglesias, V.; Laffon, B. The impact of nanotechnology in the current universal COVID-19 crisis. Let's not forget nanosafety! Nanotoxicology 2020, 14, 1013-1016. [CrossRef] [PubMed]

4. Miesen, T.J.; Engstrom, A.M.; Frost, D.C.; Ajjarapu, R.; Ajjarapu, R.; Lira, C.N.; Mackiewicz, M.R. A hybrid lipid membrane coating "shape-locks" silver nanoparticles to prevent surface oxidation and silver ion dissolution. RSC Adv. 2020, 10, 15677-15693. [CrossRef]

5. Kraśniewska, K.; Galus, S.; Gniewosz, M. Biopolymers-Based Materials Containing Silver Nanoparticles as Active Packaging for Food Applications-A Review. Int. J. Mol. Sci. 2020, 21, 698. [CrossRef]

6. Nile, S.H.; Baskar, V.; Selvaraj, D.; Nile, A.; Xiao, J.; Kai, G. Nanotechnologies in Food Science: Applications, Recent Trends, and Future Perspectives. Nano-Micro Lett. 2020, 12, 1-34. [CrossRef]

7. Salleh, A.; Naomi, R.; Utami, N.D.; Mohammad, A.W.; Mahmoudi, E.; Mustafa, N.; Fauzi, M.B. The Potential of Silver Nanoparticles for Antiviral and Antibacterial Applications: A Mechanism of Action. Nanomaterials 2020, 10, 1566. [CrossRef]

8. Iravani, S.; Korbekandi, H.; Mirmohammadi, S.V.; Zolfaghari, B. Synthesis of silver nanoparticles: Chemical, physical and biological methods. Res. Pharm. Sci. 2014, 9, 385.

9. Morales-Avila, E.; Ferro-Flores, G.; Ocampo-García, B.E.; López-Téllez, G.; López-Ortega, J.; Rogel-Ayala, D.G.; Sánchez-Padilla D. Antibacterial Efficacy of Gold and Silver Nanoparticles Functionalized with the Ubiquicidin (29-41) Antimicrobial Peptide. J. Nanomater. 2017, 2017, 1-10. [CrossRef]

10. Zhou, Y.; Kong, Y.; Kundu, S.; Cirillo, J.D.; Liang, H. Antibacterial activities of gold and silver nanoparticles against Escherichia coli and bacillus Calmette-Guérin. J. Nanobiotechnol. 2012, 10, 19. [CrossRef]

11. Bykkam, S.; Narsingam, S.; Ahmadipour, M.; Dayakar, T.; Venkateswara Rao, K.; Shilpa Chakra, C.; Kalakotla, S. Few layered graphene Sheet decorated by ZnO Nanoparticles for anti-bacterial application. Superlattices Microstruct. 2015, 83, 776-784. [CrossRef]

12. Franci, G.; Falanga, A.; Galdiero, S.; Palomba, L.; Rai, M.; Morelli, G.; Galdiero, M. Silver nanoparticles as potential antibacterial agents. Molecules 2015, 20, 8856-8874. [CrossRef] [PubMed]

13. Batista, P.S.P.; de Morais, A.M.M.B.; Pintado, M.M.E.; de Morais, R.M.S.C. Alginate: Pharmaceutical and Medical Applications; Springer: Cham, Switzerland, 2019; pp. 649-691.

14. Senturk Parreidt, T.; Müller, K.; Schmid, M. Alginate-Based Edible Films and Coatings for Food Packaging Applications. Foods 2018, 7, 170. [CrossRef] [PubMed]

15. Dias, A.M.G.C.; Hussain, A.; Marcos, A.S.; Roque, A.C.A. A biotechnological perspective on the application of iron oxide magnetic colloids modified with polysaccharides. Biotechnol. Adv. 2011, 29, 142-155. [CrossRef]

16. Yang, C.H.; Wang, L.S.; Chen, S.Y.; Huang, M.C.; Li, Y.H.; Lin, Y.C.; Chen, P.F.; Shaw, J.F.; Huang, K.S. Microfluidic assisted synthesis of silver nanoparticle-chitosan composite microparticles for antibacterial applications. Int. J. Pharm. 2016, 510, 493-500. [CrossRef]

17. Wang, W.; Meng, Q.; Li, Q.; Liu, J.; Zhou, M.; Jin, Z.; Zhao, K. Chitosan Derivatives and Their Application in Biomedicine. Int. J. Mol. Sci. 2020, 21, 487. [CrossRef]

18. Nowak, N.; Grzebieniarz, W.; Khachatryan, G.; Khachatryan, K.; Konieczna-Molenda, A.; Krzan, M.; Grzyb, J. Synthesis of Silver and Gold Nanoparticles in Sodium Alginate Matrix Enriched with Graphene Oxide and Investigation of Properties of the Obtained Thin Films. Appl. Sci. 2021, 11, 3857. [CrossRef]

19. Isawi, H. Using Zeolite/Polyvinyl alcohol/sodium alginate nanocomposite beads for removal of some heavy metals from wastewater. Arab. J. Chem. 2020, 13, 5691-5716. [CrossRef]

20. Divya, K.; Jisha, M.S. Chitosan nanoparticles preparation and applications. Environ. Chem. Lett. 2017, 16, 101-112. [CrossRef]

21. Kumar, S.; Mukherjee, A.; Dutta, J. Chitosan based nanocomposite films and coatings: Emerging antimicrobial food packaging alternatives. Trends Food Sci. Technol. 2020, 97, 196-209. [CrossRef]

22. Lou, T.; Yan, X.; Wang, X. Chitosan coated polyacrylonitrile nanofibrous mat for dye adsorption. Int. J. Biol. Macromol. 2019, 135, 919-925. [CrossRef] [PubMed]

23. Gerszberg, A.; Hnatuszko-Konka, K.; Kowalczyk, T.; Kononowicz, A.K. Tomato (Solanum lycopersicum L.) in the service of biotechnology. Plant Cell. Tissue Organ Cult. 2015, 120, 881-902. [CrossRef]

24. Raiola, A.; Rigano, M.M.; Calafiore, R.; Frusciante, L.; Barone, A. Enhancing the health-promoting effects of tomato fruit for biofortified food. Mediat. Inflamm. 2014, 2014, 139873. [CrossRef] [PubMed]

25. ZhengJing, W.; ShuWei, S.; FengHua, W.; DaLong, G. Establishment of regeneration and transformation system of Lycopersicon esculentum MicroTom. Br. Biotechnol. J. 2011, 1, 53-60. 
26. Davino, S.; Caruso, A.G.; Bertacca, S.; Barone, S.; Panno, S. Tomato Brown Rugose Fruit Virus: Seed Transmission Rate and Efficacy of Different Seed Disinfection Treatments. Plants 2020, 9, 1615. [CrossRef] [PubMed]

27. Schwarz, D.; Thompson, A.J.; Kläring, H.P. Guidelines to use tomato in experiments with a controlled environment. Front. Plant Sci. 2014, 5, 625. [CrossRef] [PubMed]

28. López, S.M.Y.; Pastorino, G.N.; Franco, M.E.E.; Medina, R.; Lucentini, C.G.; Saparrat, M.C.N.; Balatti, P.A. Microbial Endophytes that Live within the Seeds of Two Tomato Hybrids Cultivated in Argentina. Agron. 2018, 8, 136. [CrossRef]

29. Minutolo, M.; Chiaiese, P.; Di Matteo, A.; Errico, A.; Corrado, G. Accumulation of Ascorbic Acid in Tomato Cell Culture: Influence of the Genotype, Source Explant and Time of In Vitro Cultivation. Antioxidants 2020, 9, 222. [CrossRef]

30. Oceania, C.; Doni, T.; Tikendra, L.; Nongdam, P. Establishment of Efficient in vitro Culture and Plantlet Generation of Tomato (Lycopersicon esculentum Mill.) and Development of Synthetic Seeds. J. Plant Sci. 2015, 10, 15. [CrossRef]

31. Bharti, N.; Kapoor, B.; Shaunak, I.; Sharma, P.; Sharma, R. Effect of sterilization treatments on in vitro culture establishment of tomato (Solanum lycopersicum L.). IJCS 2018, 6, 1165-1168.

32. Kumer Sen, M.; Abu Hena Mostofa Jamal, M.; Nasrin, S. Sterilization factors affect seed germination and proliferation of Achyranthes aspera cultured in vitro. Environ. Exp. Biol. 2013, 11, 119-123.

33. Barampuram, S.; Allen, G.; Krasnyanski, S. Effect of various sterilization procedures on the in vitro germination of cotton seeds. Plant Cell. Tissue Organ Cult. 2014, 118, 179-185. [CrossRef]

34. Shaik, S.P.; Thomas, P. In Vitro Activation of Seed-Transmitted Cultivation-Recalcitrant Endophytic Bacteria in Tomato and Host-Endophyte Mutualism. Microorganisms 2019, 7, 132. [CrossRef] [PubMed]

35. Xu, M.; Sheng, J.; Chen, L.; Men, Y.; Gan, L.; Guo, S.; Shen, L. Bacterial community compositions of tomato (Lycopersicum esculentum Mill.) seeds and plant growth promoting activity of ACC deaminase producing Bacillus subtilis (HYT-12-1) on tomato seedlings. World J. Microbiol. Biotechnol. 2014, 30, 835-845. [CrossRef]

36. Morella, N.M.; Zhang, X.; Koskella, B. Tomato seed-associated bacteria confer protection of seedlings against foliar disease caused by pseudomonas syringae. Phytobiomes J. 2019, 3, 177-190. [CrossRef]

37. Murasnige, T.; Skoog, F. A Revised Medium for Rapid Growth and Bio Agsays with Tohaoco Tissue Cultures. Physiol. Plant 1962, 15, 473-497. [CrossRef]

38. Fisher, F.W.; Cook, N.B. Fundamentals of Diagnostic Mycology; W.B. Saunders: Philadelphia, PA, USA, 1998 ; ISBN 9780721650067.

39. Samson, R.A.; Hoekstra, E.S.; Frisvad, J.C.; Filtenborg, O. Introduction to Food and Airborne Fungi, 6th ed.; Centraalbureau voor Schimmelcultures: Utrecht, The Netherlands, 2000.

40. Samson, R.A.; Hoekstra, E.S.; Frisvad, J.C. Introduction to Food and Airborne Fungi, 7th ed.; Centraalbureau voor Schimmelcultures: Utrecht, The Netherlands, 2004.

41. St-Germain, G.; Summerbell, R. Identifying Filamentous Fungi: A Clinical Laboratory Handbook. Rev. Inst. Med. Trop. S. Paulo 1996, 45, 152. [CrossRef]

42. Khachatryan, G.; Khachatryan, K.; Krystyjan, M.; Krzan, M.; Khachatryan, L. Functional properties of composites containing silver nanoparticles embedded in hyaluronan and hyaluronan-lecithin matrix. Int. J. Biol. Macromol. 2020, 149, 417-423. [CrossRef]

43. Bajas, D.; Vlase, G.; Mateescu, M.; Grad, O.A.; Bunoiu, M.; Vlase, T.; Avram, C. Formulation and Characterization of AlginateBased Membranes for the Potential Transdermal Delivery of Methotrexate. Polymers 2021, 13, 161. [CrossRef]

44. Xu, J.; Li, Y.; Wang, H.; Zhu, M.; Feng, W.; Liang, G. Enhanced Antibacterial and Anti-Biofilm Activities of Antimicrobial Peptides Modified Silver Nanoparticles. Int. J. Nanomed. 2021, 16, 4831. [CrossRef]

45. Gerszberg, A.; Hnatuszko-Konka, K.; Kowalczyk, T.; Kononowicz, A.K. Efficient In Vitro Callus Induction and Plant Regeneration Protocol for Different Polish Tomato Cultivars. Not. Bot. Horti Agrobot. Cluj-Napoca 2016, 44, 452-458. [CrossRef]

46. García, J.L.; Troncoso, J.; Sarmiento, R.; Troncoso, A. Influence of carbon source and concentration on the in vitro development of olive zygotic embryos and explants raised from them. Plant Cell Tissue Organ Cult. 2002, 69, 95-100. [CrossRef]

47. Sahu, J.; Sahu, R.K. A Review on Low Cost Methods for In Vitro Micropropagation of Plant through Tissue Culture Technique. Pharm. Biosci. J. 2013, 1, 38-41. [CrossRef]

48. Kozai, T.; Kubota, C.; Jeong, B.R. Environmental control for the large-scale production of plants through in vitro techniques. Plant Cell Tissue Organ Cult. 1997, 51, 49-56. [CrossRef]

49. Mahna, N.; Zununi Vahed, S.; Khani, S. Plant In vitro Culture goes Nano: Nanosilver-Mediated Decontamination of Ex vitro Explants. J. Nanomed. Nanotechnol. 2013, 4, 3. [CrossRef]

50. Parzymies, M. Nano-Silver Particles Reduce Contaminations in Tissue Culture but Decrease Regeneration Rate and Slows down Growth and Development of Aldrovanda vesiculosa Explants. Appl. Sci. 2021, 11, 3653. [CrossRef]

51. Krupa-Małkiewicz, M.; Oszmiański, J.; Lachowicz, S.; Szczepanek, M.; Jaśkiewicz, B.; Pachnowska, K.; Ochmian, I. Effect of nanosilver (nAg) on disinfection, growth, and chemical composition of young barley leaves under in vitro conditions. J. Integr. Agric. 2019, 18, 1871-1881. [CrossRef]

52. Bil, W.; Krupa-Małkiewicz, M.; Figiel-Kroczyńska, M.P.J. Effect of nanosilverparticles on the growth of petunia (Petunia $\times$ atkinsiana D. don) in in vitro cultures. In Proceedings of the Badania i Rozwój Młodych Naukowców w Polsce Nauki Przyrodnicze—Flora i Fauna; Młodzi Naukowcy: Poznań, Poland, 2020; pp. 7-13. ISBN 978-83-66392-84-7.

53. Dehkourdi, E.H.; Mosavi, M. Effect of anatase nanoparticles (TiO2) on parsley seed germination (Petroselinum crispum) in vitro. Biol. Trace Elem. Res. 2013, 155, 283-286. [CrossRef] 
54. Shinde, S.; Paralikar, P.; Ingle, A.P.; Rai, M. Promotion of seed germination and seedling growth of Zea mays by magnesium hydroxide nanoparticles synthesized by the filtrate from Aspergillus niger. Arab. J. Chem. 2020, 13, 3172-3182. [CrossRef]

55. Jiang, J.; Kim, S.H.; Piao, L. The facile synthesis of $\mathrm{Cu} @ S i O 2$ yolk-shell nanoparticles via a disproportionation reaction of silica-encapsulated Cu2O nanoparticle aggregates. Nanoscale 2015, 7, 8299-8303. [CrossRef]

56. Li, F.; Lei, C.; Shen, Q.; Li, L.; Wang, M.; Guo, M.; Huang, Y.; Nie, Z.; Yao, S. Analysis of copper nanoparticles toxicity based on a stress-responsive bacterial biosensor array. Nanoscale 2012, 5, 653-662. [CrossRef] [PubMed]

57. Auría-Soro, C.; Nesma, T.; Juanes-Velasco, P.; Landeira-Viñuela, A.; Fidalgo-Gomez, H.; Acebes-Fernandez, V.; Gongora, R.; Parra, M.J.A.; Manzano-Roman, R.; Fuentes, M. Interactions of Nanoparticles and Biosystems: Microenvironment of Nanoparticles and Biomolecules in Nanomedicine. Nanomaterials 2019, 9, 1365. [CrossRef] [PubMed]

58. Mariychuk, R.; Porubská, J.; Ostafin, M.; Čaplovičová, M.; Eliašová, A. Green synthesis of stable nanocolloids of monodisperse silver and gold nanoparticles using natural polyphenols from fruits of Sambucus nigra L. Appl. Nanosci. 2020, 10, 4545-4558. [CrossRef]

59. Riaz, M.; Mutreja, V.; Sareen, S.; Ahmad, B.; Faheem, M.; Zahid, N.; Jabbour, G.; Park, J. Exceptional antibacterial and cytotoxic potency of monodisperse greener AgNPs prepared under optimized pH and temperature. Sci. Rep. 2021, 11, 1-11. [CrossRef]

60. Inbakandan, D.; Kumar, C.; Abraham, L.S.; Kirubagaran, R.; Venkatesan, R.; Khan, S.A. Silver nanoparticles with anti microfouling effect: A study against marine biofilm forming bacteria. Colloids Surf. B Biointerfaces 2013, 111, 636-643. [CrossRef]

61. Salomoni, R.; Léo, P.; Rodrigues, M.F.A. Antibacterial activity of silver nanoparticles (AgNPs) in Staphylococcus aureus and cytotoxicity effect in mammalian cells. Basic Sci. Technol. Adv. Educ. Programs 2015, 1, 851-857.

62. Xu, Y.; Gao, C.; Li, X.; He, Y.; Zhou, L.; Pang, G.; Sun, S. In Vitro Antifungal Activity of Silver Nanoparticles against Ocular Pathogenic Filamentous Fungi. J. Ocul. Pharmacol. Ther. 2013, 29, 270-274. [CrossRef]

63. Mousavi, S.A.A.; Pourtalebi, S. MSc Inhibitory Effects of Silver Nanoparticles on Growth and Aflatoxin B1 Production by Aspergillus Parasiticus. Iran. J. Med. Sci. 2015, 40, 501.

64. Bocate, K.P.; Reis, G.F.; de Souza, P.C.; Oliveira Junior, A.G.; Durán, N.; Nakazato, G.; Furlaneto, M.C.; de Almeida, R.S.; Panagio, L.A. Antifungal activity of silver nanoparticles and simvastatin against toxigenic species of Aspergillus. Int. J. Food Microbiol. 2019, 291, 79-86. [CrossRef]

65. Chen, J.; Wu, L.; Lu, M.; Lu, S.; Li, Z.; Ding, W. Comparative Study on the Fungicidal Activity of Metallic MgO Nanoparticles and Macroscale MgO Against Soilborne Fungal Phytopathogens. Front. Microbiol. 2020, 11, 365. [CrossRef]

66. Wang, L.; Hu, C.; Shao, L. The antimicrobial activity of nanoparticles: Present situation and prospects for the future. Int. J. Nanomed. 2017, 12, 1227-1249. [CrossRef] [PubMed]

67. Sinha, R.; Karan, R.; Sinha, A.; Khare, S.K. Interaction and nanotoxic effect of ZnO and Ag nanoparticles on mesophilic and halophilic bacterial cells. Bioresour. Technol. 2011, 102, 1516-1520. [CrossRef] [PubMed]

68. Żarowska, B.; Koźlecki, T.; Piegza, M.; Jaros-Koźlecka, K.; Robak, M. New Look on Antifungal Activity of Silver Nanoparticles (AgNPs). Pol. J. Microbiol. 2019, 68, 515. [CrossRef] [PubMed]

69. Żarowska, B.; Piegza, M.; Jaros-Koźlecka, K.; Koźlecki, T.; Robak, M. Antimicrobial Activity of Silver Nanoparticles; BRIA: Wrocław, Poland, 2015; p. 55. 